\title{
PENGARUH INSENTIF DAN KOMUNIKASI TERHADAP KINERJA KARYAWAN PADA PT ASIA KARET
}

\author{
Oleh : \\ Shandy Gunawan ${ }^{1)}$ Nicholas Tanuwijaya ${ }^{2)}$, Octavia Paulus ${ }^{3)}$, Linda ${ }^{4)}$ dan \\ Hendry ${ }^{5)}$ \\ Universitas Prima Indonesia, Medan 1,2,3,4,5) \\ E-Mail : \\ $\underline{\text { shandygunawan975@gmail.com }}{ }^{1)}$, nicholas tanuwijaya@yahoo.co.id ${ }^{2)}$, \\ octaviaaapaulusss@yahoo.co.id $^{3)}$, lindalie096@ gmail.com ${ }^{4)}$, \\ hendry_wijaya63@yahoo.com ${ }^{5)}$
}

\begin{abstract}
The researcher took the research object in PT. Asia Karet, research object selection was caused by the decrease of employee's performance, work results that become a benchmark for employees. Employee's performance is affected by some factors, some of them are communication and incentive. Communication within the company must run well both vertically and horizontally to reduce misinformation in working both orders from superiors or information between coworkers. Communication has an important role in efforts to achieve organizational goals, so it can be said that the success or failure of an organization is largely determined by the quality of communication possessed by people in the organization concerned. The population of this research is as many as 67 and the samples were taken by using saturated sampling and 30 employees for validity test from other companies. Research method used is quantitative method. Method of collecting data was done by using interview, questionaire, and documentation study. Analysis method used is multiple linear regression, simultaneous coefficient of determination and testing ( $F$-Test) with $F_{\text {count }}>F_{\text {table }}(40.934>3.080)$ and partially (Test- $t)$ with values for incentive variables $t$ count $>t$ table $(3.037>1.981)$ and communication ( $(2.932>1.981)$.The results show that incentives and communication simultaneously and partially have a positive and significant effect on the performance of employees at PT. Asia Karet
\end{abstract}

Keywords: Incentives, Communication and Employee Performance

\section{PENDAHULUAN}

\section{Latar Belakang}

Kinerja karyawan dipengaruhi

oleh beberapa faktor diantaranya

komunikasi dan insentif. Komunikasi dalam perusahaan harus berjalan dengan baik baik secara vertical maupun horizontal untuk mengurangi kesalahan informasi dalam bekerja baik perintah dari atasan ataupun informasi antar 
rekan kerja. Komunikasi memiliki peranan yang penting dalam usaha mencapai tujuan organisasi, sehingga dapat dikatakan bahwa sukses atau gagalnya suatu organisasi sebagian besar ditentukan oleh kualitas komunikasi yang dimiliki oleh orangorang dalam organisasi yang bersangkutan.

Komunikasi yang terjadi di dalam organisasi disebut komunikasi organisasi. Komunikasi organisasi sebagai derajat atau tingkat informasi tentang pekerjaan yang dikirimkan organisasi untuk anggota dan diantara anggota organisasi. Tujuan komunikasi dalam organisasi adalah untuk membentu saling pengertian sehingga terjadi kesetaraan kerangka referensi dan kesamaan pengalaman diantara anggota organisasi. Sehingga dengan komunikasi yang berjalan dengan baik diharapkan tidak terjadi kesalahan dalam perpindahan informasi sehingga kinerja karyawan bisa maksimal.

Selain faktor komunikasi, faktor lain yang mempengaruhi kinerja karyawan adalah insentif. Untuk dapat mengikuti segala perkembangan yang ada dan tercapainya tujuan suatu perusahaan maka perlu adanya suatu motivasi agar karyawan mampu bekerja dengan baik, dan salah satu motivasi itu adalah dengan memenuhi keinginankeinginan karyawan antara lain: insentif yang baik, pekerjaan yang aman, suasana kerja yang kondusif, penghargaan terhadap pekerjaan yang dilakukan, pimpinan yang adil dan bijaksana, pengarahan dan perintah yang wajar, organisasi atau tempat kerja yang dihargai masyarakat. Perusahaan harus mengupayakan insentif yang besarannya proporsional dan juga bersifat progresif yang artinya sesuai dengan jenjang karir, karena insentif sangat diperlukan untuk memacu kinerja para karyawan agar selalu berada pada tingkat tertinggi (optimal) sesuai kemampuan masing-masing.

PT Asia Karet merupakan sebuah perusahaan yang bergerak dibidang produksi dan penjualan produk yang bahan utamanya adalah karet. Informasi produk : Rubber Hose, Slang Automotive, Rubber Sheet Packing dan Kertas Nasi Laminating, Tapak Sepatu, Canvas Shoes/Sandal Jepit. Proses produksinya dari bahan mentah (getah karet) menjadi bahan jadi. Dalam kegiatannya perusahaan mengalami masalah berupa penurunan penjualan yang disebabkan menurunnya kinerja karyawan pada perusahaan. 
Berdasarkan uraian dan latar belakang diatas, maka peneliti tertarik untuk mengambil judul skripsi dengan judul : "Pengaruh Komunikasi dan Insentif terhadap Kinerja di PT Asia Karet."

\section{Identifikasi Masalah}

Berdasarkan latar belakang masalah yang telah diuraikan di atas, maka identifikasi masalah dalam penelitian ini adalah :

1. Komunikasi yang kurang baik sehingga menyebabkan kesalahan karyawan akibat komunikasi terjadi dan menimbulkan konflik dalam lingkungan kerja.

2. Adanya perbedaan perlakuan dalam memberikan insentif menyebabkan karyawan tidak termotivasi dalam bekerja dan cenderung menunda pekerjaan.

3. Kinerja karyawan pada PT Asia Karet Medan menurun karena komunikasi yang tidak berjalan baik dan menurunnya motivasi karyawan karena perbedaan perlakuan dalam perhitungan insentif.

\section{Perumusan Masalah}

Berdasarkan latar belakang yang telah dikemukakan, maka menjadi permasalahan dalam penelitian ini:
1. Bagaimana pengaruh komunikasi terhadap kinerja karyawan pada PT Asia Karet Medan?

2. Bagaimana pengaruh insentif terhadap kinerja karyawan pada PT Asia Karet Medan?

3. Bagaimana pengaruh komunikasi dan insentif terhadap kinerja karyawan pada PT Asia Karet Medan?

\section{Tujuan Penelitian}

Tujuan dari penelitian ini adalah untuk:

1. Menguji dan menganalisis pengaruh komunikasi terhadap kinerja karyawan pada PT Asia Karet Medan.

2. Menguji dan menganalisis pengaruh insentif terhadap kinerja karyawan pada PT Asia Karet Medan.

3. Menguji dan menganalisis pengaruh komunikasi dan insentif terhadap kinerja karyawan pada PT Asia Karet Medan.

\section{Manfaat Penelitian}

Manfaat yang diharapkan oleh peneliti dari penelitian ini sebagai berikut:

\section{Bagi Peneliti}

Sebagai peningkatan pengetahuan dan wawasan bagi peneliti khususnya yang berkaitan dengan pengaruh komunikasi dan insentif terhadap kinerja karyawan pada 
PT Asia Karet Medan.

2. Bagi Universitas Prima Indonesia Sebagai bahan kajian ilmu dan menambah referensi penelitian bagi Program Studi S-1 Manajemen Fakultas Ekonomi UNPRI

3. Bagi Perusahaan

Sebagai bahan masukan dan pertimbangan bagi pihak perusahaan PT Asia Karet Medan untuk mengevaluasi kinerja karyawan perusahaan dengan memperhatikan peran pimpinan dan adanya insentif kerja antar karyawan.

4. Bagi Peneliti Selanjutnya

Sebagai bahan referensi atau perbandingan bagi peneliti selanjutnya yang akan melakukan penelitian di masa yang akan datang.

\section{Teori Pengaruh Komunikasi}

\section{Terhadap Kinerja}

Menurut Kaswan (2012:259), untuk itu diperlukan komunikasi yang efektif dalam organisasi. Ketika komunikasi efektif, komunikasi itu cenderung mendorong kinerja dan kepuasan kerja yang lebih baik.

Menurut Siswandi (2011:128), komunikasi yang efektif dan efisien mempunyai arti yang sangat penting bagi manajemen di dalam melaksanakan fungsinya untuk merencanakan, mengorganisir, melaksanakan, mengarahkan dan mengawasi semua kinerja organisasi.

Menurut Feriyanto dan Triana (2015:155), komunikasi tidak hanya penting untuk manusia tetapi juga penting untuk sistem pengendalian manajemen yang merupakan alat untuk mengarahkan, memotivasi, memonitor atau mengamati, serta evaluasi pelaksanaan manajemen perusahaan yang mencoba mengarahkan pada tujuan organisasi dalam perusahaan. Hal itu dimaksudkan agar kinerja yang dilakukan oleh pihak manajemen perusahaan dapat berjalan lebih efisien dan lancar.

\section{Teori Pengaruh Insentif Terhadap} Kinerja Karyawan

Menurut Kasmir (2016:242), insentif merupakan rangsangan yang diberikan untuk mendorong karyawan meningkatkan kinerja, sehingga dengan pemberian insentif, kinerja karyawan akan meningkat.

Menurut Wibowo (2016 : 302), pada dasarnya, setiap pekerja yang telah memberikan kinerja terbaiknya mengharapkan imbalan di samping gaji dan upah sebagai tambahan berupa insentif atas prestasi yang telah diberikannya. Dengan demikian, apabila organisasi dapat memberikannya, akan 
meningkatkan motivasi, partisipasi dan membangun saling pengertian dan saling mempercayai antara pekerja dan atasan.

Menurut Priansa (2016 : 336), insentif merupakan elemen atau balas jasa yang diberikan secara tidak tetap atau bersifat variabel tergantung pada kinerja pegawai. Insentif merupakan salah satu motivator penting yang dapat memberikan rangsangan kepada pergawai untuk bekerja lebih optimal. Melalui insentif diharapkan pegawai akan mampu berpartisipasi lebih tinggi dalam melaksanakan tugas organisasi.

\section{METODE PELAKSANAAN}

\section{Tempat dan Waktu Penelitian}

Lokasi penelitian dilakukan pada PT Asia Karet yang beralamat di Jalan Klambir V No. 73 Kampung Lalang, Sunggal, Deli Serdang. Kegiatan penelitian dilakukan pada bulan Juli 2018 sampai dengan Desember 2018.

\section{Metode Penelitian}

Penelitian ini menggunakan pendekatan penelitian kuantitatif. Menurut Sugiyono (2010:13) Penelitian kuantitatif dapat diartikan sebagai metode penelitian yang berlandaskan pada filsafat positivisme, digunakan untuk meneliti pada populasi atau sampel tertentu.

\section{Pendekatan Penelitian}

Penelitian ini menggunakan pendekatan penelitian kuantitatif. Menurut Sugiyono (2010:13) Penelitian kuantitatif dapat diartikan sebagai metode penelitian yang berlandaskan pada filsafat positivisme, digunakan untuk meneliti pada populasi atau sampel tertentu.

\section{Jenis Penelitian}

Jenis penelitian ini adalah metode kuantitatif. Menurut Sugiyono (2010:37), metode penelitian kuantitatif cocok digunakan untuk penelitian yang masalahnya sudah jelas, dan umumnya dilakukan pada populasi yang luas sehingga hasil penelitian kurang mendalam. Metode kuantitatif cocok untuk menguji hipotesis/teori.

\section{Sifat Penelitian}

Sifat penelitian yang dilakukan yaitu deskriptif explanatory. Menurut Sugiyono (2010:10), penelitian explanatory merupakan penelitian yang bermaksud menjelaskan kedudukan variabel-variabel yang diteliti dan hubungannya antara satu variabel dengan variabel lain.

\section{Populasi dan Sampel}

Populasi

Menurut Sugiyono (2010:115) menyatakan bahwa populasi adalah wilayah generalisasi yang terdiri dari 
objek atau subjek yang mempunyai kualitas dan karakteristik tertentu yang ditetapkan oleh peneliti untuk dipelajari dan kemudian ditarik kesimpulannya.

\section{Sampel}

Menurut Sugiyono (2012:81), "Sampel adalah bagian dari jumlah dan karakteristik yang dimiliki oleh populasi tersebut". Teknik sampel yang digunakan dalam penelitian adalah sampling jenuh. Menurut Sugiyono (2012:85), “Sampling jenuh adalah teknik penentuan sampel bila semua anggota populasi sebagai sampel". Jumlah sampel yang digunakan oleh peneliti adalah seluruh pelanggan PT. Asia Karet yang berjumlah 67 karyawan dan sebanyak 30 responden dari perusahaan PT. ASIA SUKSES PERKASA ABADI untuk uji validitas dan reliabilitas.

\section{Teknik Pengumpulan Data}

Adapun teknik pengumpulan data dilakukan dengan cara :

1. Wawancara

2. Kuesioner

3. Studi dokumentasi

\section{Jenis dan Sumber Data}

Sumber data yang diperlukan dalam penelitian ini adalah :
1. Data primer

2. Data sekunder

\section{Identifikasi dan Definisi Operasional} Variabel Penelitian

Tabel Identifikasi \& Definisi Operasional Variabel Penelitian

\begin{tabular}{|c|c|c|c|}
\hline $\begin{array}{c}\text { Variabe } \\
1\end{array}$ & Definisi Variabel & Indikator Variabel & $\begin{array}{l}\text { Skala } \\
\text { Ukur }\end{array}$ \\
\hline $\begin{array}{l}\text { Komuni } \\
\text { kasi }\left(\mathrm{X}_{1}\right)\end{array}$ & $\begin{array}{l}\text { Komunikasi adalah } \\
\text { suatu proses } \\
\text { penyampaian informasi } \\
\text { dari pengirim ke } \\
\text { penerima pesan dengan } \\
\text { menggunakan berbagai } \\
\text { media yang efektif } \\
\text { sehingga pesan tersebut } \\
\text { dapat dengan jelas dan } \\
\text { mudah dipahami oleh } \\
\text { penerima pesan } \\
\text { tersebut. Bangun } \\
\text { Sumber : Bar } \\
(2014: 361),\end{array}$ & $\begin{array}{l}\text { 1. Keterbukaan } \\
\text { 2. Empati } \\
\text { 3. Dukungan } \\
\text { 4. Kepositifan } \\
\text { 5. Kesamaan } \\
\text { Sumber : Herlambang } \\
(2014: 89-90)\end{array}$ & Likert \\
\hline $\begin{array}{c}\text { Insentif } \\
\left(\mathrm{X}_{2}\right)\end{array}$ & 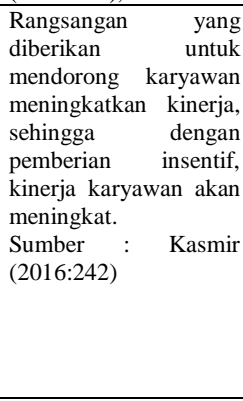 & 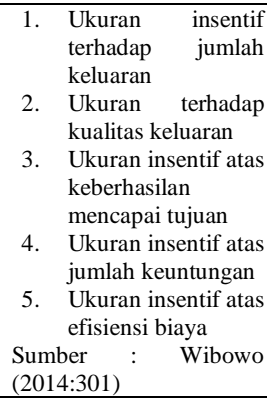 & Likert \\
\hline $\begin{array}{l}\text { Kinerja } \\
(\mathrm{Y})\end{array}$ & $\begin{array}{l}\text { Kinerja adalah catatan } \\
\text { mengenai akibat-akibat } \\
\text { yang dihasilkan pada } \\
\text { sebuah fungsi } \\
\text { pekerjaan atau } \\
\text { aktivitas selama } \\
\text { periode tertentu yang } \\
\text { berhubungan dengan } \\
\text { tujuan organisasi. } \\
\begin{array}{l}\text { Sumber : Umam } \\
(2012: 186)\end{array}\end{array}$ & $\begin{array}{lll}\text { 1. } & \text { Kualitas yang } \\
& \text { dihasilkan } & \\
\text { 2. } & \text { Kuantitas } & \text { yang } \\
& \text { dihasilkan } & \\
\text { 3. Waktu kerja } & \\
\text { 4. Kerja sama } & \\
\text { Sumber : Sutrisno } \\
(2013: 172)\end{array}$ & Likert \\
\hline
\end{tabular}

\section{Uji Validitas dan Reliabilitas}

\section{Instrumen Variabel}

Menurut Ghozali (2013:52), uji validitas digunakan untuk mengukur sah atau valid tidaknya suatu kuesioner. Suatu kuesioner dikatakan valid jika pertanyaan pada kuesioner mampu untuk mengungkapkan sesuatu yang akan diukur oleh kuesioner tersebut. Dalam memberikan interpretasi terhadap koefisien korelasi. 
Menurut Sugiyono (2010 : 188-

189) Biasanya syarat minimum untuk dianggap memenuhi syarat adalah kalau $\mathrm{r}=0,3$ ". Jadi kalau korelasi antara butir dengan skor total kurang dari 0,3 maka butir dalam instrumen tersebut dinyatakan tidak valid

Untuk menguji ketetapan kuesioner, akan dilakukan pretest terhadap 30 orang karyawan di luar responden yang dipilih dalam penelitian ini. Uji validitas dilakukan dengan bantuan program software SPSS (Statistical Package for Social Science). Uji validitas dilakukan dengan metode sekali ukur (one shot methods), dimana pengukuran dengan metode ini cukup dilakukan satu kali. Jumlah pertanyaan kuesioner sebanyak 28 pertanyaan. Dengan setiap pertanyaan yang diajukan ke responden memiliki nilai lebih besar dari 0,361 dimana hasil ini menyatakan pernyataan dari setiap indikator pada semua variabel dinyatakan telah valid.

\section{Menurut Ghozali (2013:47)} menyatakan bahwa suatu kuesioner dikatakan reliable atau handal jika jawaban seseorang terhadap pernyataan adalah konsisten atau stabil dari waktu ke waktu. Pengujian dilakukan dengan cara mencobakan kuesioner sekali saja, kemudian data yang diperoleh dianalisis dengan teknik tertentu, dalam hal ini teknik yang digunakan adalah teknik Cronbach Alpha $(\alpha)$. Suatu variabel dikatakan reliable jika memberikan nilai Cronbach Alpha $>0.70$

\section{Tabel Hasil Uji Reliabilitas Instrumen Variabel}

\begin{tabular}{|l|c|c|}
\hline \multicolumn{1}{|c|}{ Variabel } & $\begin{array}{c}\text { Nilai } \\
\text { Realibilitas }\end{array}$ & $\begin{array}{c}\text { Keteranga } \\
\mathbf{n}\end{array}$ \\
\hline Variabel Komunikasi $\left(\mathrm{X}_{1}\right)$ & 0,836 & Reliabel \\
\hline Variabel Insentif $\left(\mathrm{X}_{2}\right)$ & 0,849 & Reliabel \\
\hline Variabel Kinerja (Y) & 0,826 & Reliabel \\
\hline
\end{tabular}

\section{HASIL DAN PEMBAHASAN}

\section{Hasil Penelitian}

\section{Gambaran Umum Perusahaan}

PT Asia Karet merupakan sebuah perusahaan yang bergerak dibidang produksi dan penjualan produk yang bahan utamanya adalah karet. Informasi produk : Rubber Hose, Slang Automotive, Rubber Sheet Packing dan Kertas Nasi Laminating, Tapak Sepatu, Canvas Shoes/Sandal Jepit. Proses produksinya dari bahan mentah (getah karet) menjadi bahan jadi.

\section{Analisis Statistik Deskriptif}

Pada penelitian di PT Asia Karet, variabel bebas (independent variable) yang diamati adalah Komunikasi $\left(\mathrm{X}_{1}\right)$ dan Insentif $\left(\mathrm{X}_{2}\right)$ sedangkan varibel terikat (dependent variable) adalah Kinerja Karyawan (Y). 
Tabel Hasil Analisis Statistik

Deskriptif

Descriptive Statistics

\begin{tabular}{|l|r|r|r|r|c|}
\hline & & $\begin{array}{c}\text { Minimu } \\
\mathrm{m}\end{array}$ & $\begin{array}{c}\text { Maximu } \\
\mathrm{m}\end{array}$ & Mean & $\begin{array}{c}\text { Std. } \\
\text { Deviatio } \\
\mathrm{n}\end{array}$ \\
\hline Komunikasi & 67 & 18.00 & 46.00 & 30.9552 & 7.63650 \\
Insentif & 67 & 19.00 & 45.00 & 30.5970 & 7.41428 \\
Kinerja & 67 & 14.00 & 37.00 & 25.2985 & 6.72403 \\
Valid N & 67 & & & & \\
(listwise) & & & & & \\
\hline
\end{tabular}

Sumber : Hasil Penelitian, 2019

Pada Tabel diketahui bahwa variabel Komunikasi $\left(\mathrm{X}_{1}\right)$ dengan sampel sebanyak 67 orang memiliki rata-rata sebesar 30.9552 nilai minimum 18.00 dan maximum sebesar 46.00 dengan standar deviasi 7.63650. Nilai minimum 18 dari nomor responden 31 dan maximum 46 dari nomor responden 15.

Variabel Insentif $\left(\mathrm{X}_{2}\right)$ dengan sampel sebanyak 67 orang memiliki rata-rata sebesar 30.5970 nilai minimum 19.00 dan maximum sebesar 45.00 dengan standar deviasi 7.41428. Nilai minimum 19 dari nomor responden 29,40 dan maximum 45 dari nomor responden 8 .

Variabel Kinerja Karyawan (Y) dengan sampel sebanyak 67 orang memiliki rata-rata sebesar 25.2985 , nilai minimum 14.00 dan maximum sebesar 37.00 dengan standar deviasi 6.72403 . Nilai minimum 14 dari nomor responden 22 dan maximum 37 dari nomor responden 17 dan 64.

\section{Pengujian Asumsi Klasik}

\section{Uji Normalitas}

Untuk mendeteksi apakah residual berdistribusi normal atau tidak akan ditunjukkan dengan analisis grafik dan statistik. Analisis grafik yaitu grafik histogram dan grafik Normal Probability Plot.

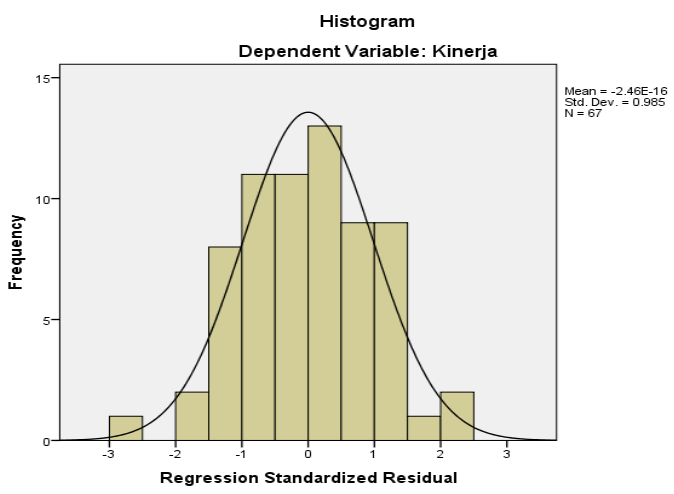

Sumber: Hasil Penelitian, 2019 (data diolah)

Gambar Hasil Pengujian

\section{Normalitas Grafik Histogram}

Dari Gambar IV.2 memperlihatkan bahwa data menyebar dan membentuk lonceng. Hal ini menunjukkan pola distribusi normal, maka model regresi dianggap memenuhi asumsi normalitas.

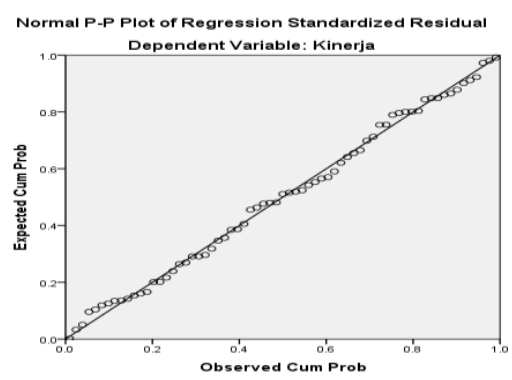

Sumber : Hasil Penelitian, 2019 (data diolah)

Gambar IV.3 Hasil Pengujian Normalitas Grafik Histogram

Pada Gambar IV.3 menunjukkan

data menyebar disekitar garis diagonal. 
Hal ini menjelaskan bahwa data berdistribusi normal. Adapun untuk menguji uji normalitas dalam perhitungan statistik yaitu menggunakan uji One Sample Kolmogorov Smirnov. Hasil uji One Kolmogorov Smirnov dapat dilihat pada Tabel

Tabel Hasil Pengujian Normalitas One Sample Kolmogorov-Smirnov Test One-Sample Kolmogorov-Smirnov Test

\begin{tabular}{|ll|r|}
\hline & & $\begin{array}{r}\text { Unstandardized } \\
\text { Residual }\end{array}$ \\
\hline $\mathrm{N}$ & Mean & 67 \\
Normal & Std. & .0000000 \\
Parameters & Deviation & 4.50794388 \\
Most Extreme & Absolute & .066 \\
Differences & Positive & .066 \\
& Negative & -.039 \\
Test Statistic & & .066 \\
Asymp. Sig. (2-tailed) & & $.200^{\mathrm{c}, \mathrm{a}}$ \\
\hline
\end{tabular}

a. Test distribution is Normal.

b. Calculated from data.

c. Lilliefors Significance Correction.

d. This is a lower bound of the true significance.

Sumber : Hasil Penelitian, 2019 (data diolah)

Berdasarkan hasil output pada

Tabel diperoleh nilai (Asymp. Sig. 2-

tailed) sebesar 0.200. Karena signifikansi lebih besar dari 5\% (0.05) maka residual terdistribusi dengan normal.

\section{Uji Multikolineritas}

Uji multikolinearitas digunakan untuk mengetahui korelasi antar variabel independen dan ini dapat dilihat dari Nilai Tolerance dan Variance Inflation Factor (VIF) dengan catatan apabila VIF > 10 maka diduga mempunyai persoalan multikolineritas dan apabila VIF < 10 maka tidak terjadi multikolineritas, Sedangkan nilai Tolerance dikatakan lolos bila nilai Tolerance < 1 Berdasarkan hasil pengolahan SPSS dilihat pada Tabel

Tabel

Hasil Uji Multikolinearitas Coefficients $^{\mathrm{a}}$

\begin{tabular}{|ll|r|r|}
\hline \multirow{2}{*}{ Model } & \multicolumn{2}{|c|}{ Collinearity Statistics } \\
\cline { 3 - 4 } & & Tolerance & \multicolumn{1}{c|}{ VIF } \\
\hline 1 & (Constant) & & \\
& Komunikasi & .388 & 2.579 \\
& Insentif & .388 & 2.579 \\
\hline
\end{tabular}

a. Dependent Variable: Kinerja

Sumber: Hasil Penelitian, 2019 (data diolah) Pada Tabel hasil variabel komunikasi dan insentif memiliki nilai VIF sebesar 2.579 lebih kecil dari 10 dan nilai tolerance sebesar 0.388 mendekati 1. Hal ini menunjukkan tidak terjadi gejala multikolinearitas.

\section{Uji Heteroskedastisitas}

Adapun hasil pengujian heteroskedastisitas dengan grafik Scatter Plot dapat dilihat pada Gambar IV.4.

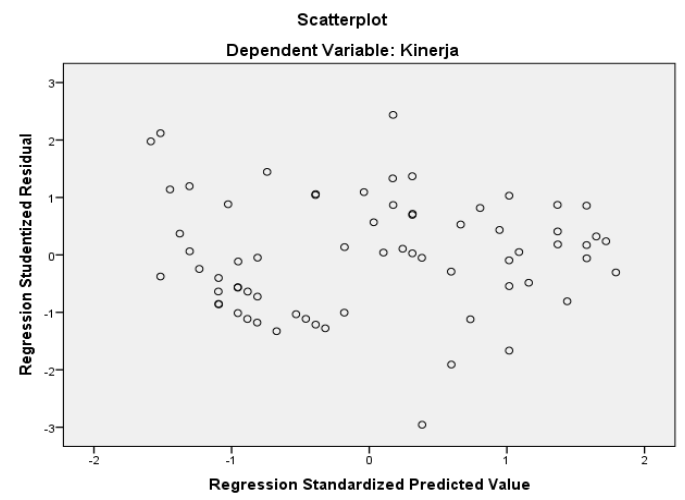

Sumber: Hasil Penelitian, 2019 (data diolah)

\section{Gambar IV.4 Uji Heteroskedastisitas}

Pada Gambar IV.4, terlihat titik yang menyebar yang tidak membentuk 
pola-pola tertentu dan tersebar baik di atas angka 0 dan berdasarkan gambar tersebut maka tidak terjadi heteroskedastisitas sehingga model regresi layak dipakai untuk memprediksi kinerja karyawan berdasarkan variabel independen. Adapun uji heterokedastisitas dengan menggunakan statistik yaitu dengan metode Uji Glejser.

Tabel

Hasil Pengujian Heteroskedastisitas Glejser Coefficients $^{\mathrm{a}}$

\begin{tabular}{|c|c|c|c|}
\hline \multirow[b]{2}{*}{ Model } & $\begin{array}{c}\text { Standardized } \\
\text { Coefficients }\end{array}$ & & \\
\hline & Beta & $t$ & Sig. \\
\hline $\begin{array}{ll}1 & \text { (Consta } \\
\text { nt) }\end{array}$ & & 4.038 & .000 \\
\hline $\begin{array}{l}\text { Komuni } \\
\text { kasi }\end{array}$ & -.126 & -.640 & .524 \\
\hline Insentif & -.094 & -.479 & .634 \\
\hline
\end{tabular}

a. Dependent Variable: ABSUT

Sumber: Hasil Penelitian, 2019 (data diolah)

Dari Tabel di atas, dapat

diketahui bahwa nilai probabilitas (Sig.) untuk variabel komunikasi adalah sebesar 0.524 dan variabel insentif adalah sebesar 0.634. Hal ini terlihat bahwa nilai signifikannya di atas tingkat kepercayaan 5\% (0,05), maka model regresi tidak mengandung adanya heteroskedastisitas.

\section{Hasil Analisis Data}

\section{Analisis Persamaan Regresi Linear}

\section{Berganda}

Model analisis data dalam penelitian ini merupakan analisis regresi berganda (multiple regretion).

Berdasarkan hasil persamaan regresi linear berganda diperoleh hasil seperti Tabel

\section{Tabel}

Hasil Uji Regresi Linier Berganda Coefficients $^{\mathrm{a}}$

\begin{tabular}{|c|c|c|c|c|c|}
\hline \multirow[b]{2}{*}{ Model } & \multicolumn{2}{|c|}{$\begin{array}{l}\text { Unstandardize } \\
\text { d Coefficients }\end{array}$} & \multirow{2}{*}{$\begin{array}{c}\begin{array}{c}\text { Standardiz } \\
\text { ed } \\
\text { Coefficient } \\
\text { s }\end{array} \\
\text { Beta }\end{array}$} & \multirow[b]{2}{*}{$\mathrm{t}$} & \multirow[b]{2}{*}{ Sig } \\
\hline & $\mathrm{B}$ & $\begin{array}{l}\text { Std. } \\
\text { Error }\end{array}$ & & & \\
\hline $\begin{array}{l}1 \text { (Consta } \\
\text { nt) }\end{array}$ & 3.477 & 2.475 & & 1.405 & $\begin{array}{r}.16 \\
5\end{array}$ \\
\hline $\begin{array}{l}\text { Komuni } \\
\text { kasi }\end{array}$ & .355 & .117 & .404 & 3.037 & $\begin{array}{r}.00 \\
3\end{array}$ \\
\hline Insentif & .354 & .121 & .390 & 2.932 & $\begin{array}{r}.00 \\
5\end{array}$ \\
\hline
\end{tabular}

a. Dependent Variable: Kinerja

Sumber: Hasil Penelitian, 2019 (data diolah)

Berdasarkan Tabel maka persamaan regresi linier berganda dalam penelitian ini sebagai berikut:

Kinerja Karyawan $=3.477+0.355$

\section{Komunikasi + 0,354 Insentif}

1. Nilai konstanta a sebesar 6.049 artinya bahwa jika tidak terdapat variabel komunikasi $\left(\mathrm{X}_{1}\right)$ dan insentif $\left(\mathrm{X}_{2}\right)$ dianggap konstan, 0 maka kinerja karyawan pada PT. Asia Karet akan bernilai sebesar 6.049 satuan.

2. Variabel komunikasi $\left(\mathrm{X}_{1}\right)$ sebesar 0.354 yang artinya bahwa setiap kenaikan variabel komunikasi sebesar 1 satuan, maka nilai pada kinerja karyawan pada PT. Asia Karet akan naik sebesar 0.354 satuan 
dengan asumsi bahwa variabel yang lain tetap.

3. Variabel insentif $\left(\mathrm{X}_{2}\right)$ sebesar 0.280 yang artinya bahwa setiap kenaikan variabel insentif sebesar 1 satuan, maka nilai pada kinerja karyawan pada PT. Asia Karet akan naik sebesar 0.280 satuan dengan asumsi bahwa variabel yang lain tetap.

\section{Koefisien Determinasi $\left(\mathbf{R}^{2}\right)$}

Hasil uji koefisien determinasi dapat dilihat pada Tabel

Tabel

Nilai Koefisien Determinasi ( $R$ Square)

Model Summary

\begin{tabular}{|l|c|r|r|r|}
\hline Model & $\mathrm{R}$ & $\begin{array}{c}\mathrm{R} \\
\text { Square }\end{array}$ & $\begin{array}{c}\text { Adjusted } \\
\text { R Square }\end{array}$ & $\begin{array}{c}\text { Std. Error of } \\
\text { the Estimate }\end{array}$ \\
\hline 1 & $.749^{\mathrm{a}}$ & .561 & .548 & 4.52294 \\
\hline
\end{tabular}

a. Predictors: (Constant), Insentif, Komunikasi

b. Dependent Variable: Kinerja

Sumber: Hasil Penelitian, 2019 (data diolah)

$$
\text { Berdasarkan Tabel nilai }
$$

Adjusted $R$ Square adalah 0,548 artinya bahwa kemampuan variasi variabel komunikasi $\left(\mathrm{X}_{1}\right)$ dan insentif $\left(\mathrm{X}_{2}\right)$ dapat menjelaskan variasi dari kinerja karyawan pada PT. Sinar Angkasa Sejahtera adalah sebesar $54,8 \%$ dan sisanya sebesar $45,2 \%$ dijelaskan oleh variabel-variabel independen yang tidak diteliti seperti kepemimpinan, disiplin dan kepuasan kerja.

\section{Pengujian Hipotesis Secara Simultan}

(Uji-F)

$$
\text { Uji F pada dasarnya }
$$

menunujukkan apakah semua variabel independen atau bebas yang dimasukkan dalam model mempunyai pengaruh secara bersama-sama terhadap variabel dependen/terikat.

$\mathrm{df}($ pembilang $)=\mathrm{k}-1$

df $($ penyebut $)=\mathrm{n}-\mathrm{k}$

Keterangan :

$\mathrm{N}=$ jumlah sampel penelitian

$\mathrm{K}=$ jumlah variabel bebas dan terikat

Pada penelitian ini diketahui jumlah sampel (n) adalah 64 dan keseluruhan variabel (k) adalah 3, sehingga diperoleh :

1) $\mathrm{Df}($ pembilang $)=\mathrm{k}-1 \quad \mathrm{df}$ $($ pembilang $)=3-1=2$

2) Df (penyebut) $=n-k \quad d f$ (penyebut) $=67-3=64$

Nilai $F_{\text {hitung }}$ akan diperoleh dengan menggunakan bantuan software SPSS. Kemudian akan dibandingkan dengan nilai $\mathrm{F}_{\text {tabel }}$ pada tingkat $\mathrm{a}=5 \%$ $(2: 64)=3,08$.

\section{Tabel}

Hasil Pengujian Hipotesis Secara Simultan ANOVA $^{a}$

\begin{tabular}{|l|r|r|r|r|r|}
\hline Model & \multicolumn{1}{|c|}{$\begin{array}{c}\text { Sum of } \\
\text { Squares }\end{array}$} & \multicolumn{1}{c|}{ df } & \multicolumn{1}{c|}{$\begin{array}{c}\text { Sean } \\
\text { Square }\end{array}$} & F & Sig. \\
\hline $1 \quad$ Regressi & 1674.784 & 2 & 837.392 & 40.934 & $.000^{\mathrm{b}}$ \\
on & 1309.246 & 64 & 20.457 & & \\
$\quad$ Residual & 2984.030 & 66 & & & \\
$\quad$ Total & & & \\
\hline
\end{tabular}

a. Dependent Variable: Kinerja

b. Predictors: (Constant), Insentif, Komunikasi

Sumber: Hasil Penelitian, 2019 (data diolah)

Pada Tabel diperoleh hasil

$\mathrm{F}_{\text {Hitung }} 40.934$ sedangkan $\mathrm{F}_{\text {Tabel }}$ pada $\alpha=$ 0,05 diperoleh dari sumber probabilitas 
$\mathrm{F}_{\text {tabel }}$ yang tersedia yaitu 3,08 dari hasil ini diketahui $\mathrm{F}$ hitung $>\mathrm{F}$ tabel, dan signifikansi 0,000 atau lebih kecil dari $\mathrm{a}=0,05$ jadi posisi titik uji signifikansi berada pada wilayah penolakan $\mathrm{H}_{\mathrm{o}}$ atau dapat disimpulkan $\mathrm{H}_{\mathrm{a}}$ diterima yang artinya bahwa variabel komunikasi dan insentif secara bersama-sama berpengaruh positif dan signifikan terhadap variabel kinerja karyawan pada PT. Asia Karet

\section{Pengujian Hipotesis Secara Parsial}

(Uji t)

Uji-t dilakukan untuk melihat pengaruh variabel bebas yaitu komunikasi dan insentif secara parsial terhadap kinerja karyawan pada PT. Asia Karet.

\begin{tabular}{|c|c|c|c|c|}
\hline Hasil Uji & $\begin{array}{r}\text { Iipote } \\
\text { Coe }\end{array}$ & $\begin{array}{l}\text { bbel } \\
\text { is Secar } \\
\text { ji t } t \\
\text { ficients }^{a}\end{array}$ & Pars & \\
\hline & $\begin{array}{r}\text { Unst } \\
\text { Co }\end{array}$ & $\begin{array}{l}\text { ndardized } \\
\text { fficients }\end{array}$ & & \\
\hline Model & $\mathrm{B}$ & Std. Error & $\mathrm{t}$ & Sig. \\
\hline $\begin{array}{l}1 \text { (Constan } \\
\text { t) }\end{array}$ & 3.477 & 2.475 & 1.405 & .165 \\
\hline $\begin{array}{l}\text { Komunik } \\
\text { asi }\end{array}$ & .355 & .117 & 3.037 & .003 \\
\hline Insentif & .354 & .121 & 2.932 & .005 \\
\hline
\end{tabular}

a. Dependent Variable: Kinerja

Sumber: Hasil Penelitian, 2019 (data diolah)

Dengan sampel sebesar 67 dan taraf $\operatorname{sig} \alpha=5 \%$ maka nilai $t_{\text {tabel }}$ adalah sebesar 1.981. Pada Tabel IV.15, hasil uji parsial diperoleh hasil sebagai berikut:

1. Nilai $\mathrm{t}$ hitung untuk variabel komunikasi (3.037) lebih dominan dibandingkan dengan nilai t tabel $(1,981)$ atau nilai sig $t$ untuk variabel komunikasi $(0,000)$ lebih kecil dari $\alpha(0,05)$. Berdasarkan hasil yang diperoleh maka menolak Ho dan menerima $\mathrm{H}_{\mathrm{a}}$ untuk variabel komunikasi. Dengan demikian, secara parsial komunikasi berpengaruh positif dan signifikan terhadap kinerja karyawan. Hal ini memberi arti bahwa komunikasi memberikan dampak pada kinerja karyawan pada PT. Asia Karet.

2. Nilai $t$ hitung untuk variabel insentif (2.932) lebih dominan dibandingkan dengan nilai $\mathrm{t}$ tabel $(1,981)$, atau nilai sig $\mathrm{t}$ untuk variabel insentif $(0,000)$ lebih kecil dari $\alpha(0,05)$. Berdasarkan hasil yang diperoleh maka menolak $\mathrm{H}_{0}$ dan menerima $\mathrm{H}_{\mathrm{a}}$ untuk variabel insentif. Dengan demikian, secara parsial insentif berpengaruh positif dan signifikan terhadap kinerja karyawan. Hal ini memberi arti bahwa insentif karyawan di perusahaan memberikan dampak pada kinerja karyawan pada PT. Asia Karet.

3.

\section{KESIMPULAN DAN SARAN}

\section{Kesimpulan}

Berdasarkan hasil penelitian dan pembahasan yang telah diuraikan pada 
bab sebelumnya, maka dapat ditarik kesimpulan sebagai berikut:

1. Pengujian hasil secara parsial menunjukkan bahwa

Komunikasi berpengaruh positif dan signifikan terhadap Kinerja Karyawan PT. Asia Karet Medan dengan nilai $\mathrm{t}$ hitung $>\mathrm{t}$ tabel $(3,037>1,981)$.

2. Pengujian hasil secara parsial menunjukkan bahwa Insentif berpengaruh positif dan signifikan terhadap Kinerja Karyawan PT. Asia Karet Medan dengan nilai $\mathrm{t}$ hitung $>\mathrm{t}$ tabel $(2,932>1,981)$.

3. Pengujian hasil secara simultan menunjukkan bahwa Komunikasi dan Insentif berpengaruh positif dan signifikan terhadap Kinerja Karyawan PT. Asia Karet Medan dengan nilai $\mathrm{F}_{\text {hitung }}>\mathrm{F}$ tabel $(40,934>3,080)$ dan nilai koefisien determinasi sebesar $54,8 \%$ dan sisanya sebesar $45,2 \%$ dijelaskan oleh variabelvariabel independen yang tidak diteliti seperti kepemimpinan, disiplin dan kepuasan kerja.

\section{Saran}

Berdasarkan kesimpulan sebelummya, maka peneliti menyarankan sebagai berikut:
1. Bagi Peneliti atas hasil penelitian ini dapat sebagai bahan pengetahuan untuk memperluas wawasan penelitian dalam bidang ilmu manajemen sumber daya manusia.

2. Bagi peneliti selanjutnya, agar lebih mengembangkan teoriteori menyangkut variabel yang diduga memiliki hubungan dengan kinerja karyawan seperti: kepemimpinan, disiplin dan kepuasan kerja.

3. Bagi perusahaan harus memperbaiki alur komunikasi yang ada di perusahaan. Dengan perbaikan komunikasi yang ada di perusahaan akan membentuk alur kerja yang lebih baik dan teratur. Selain itu untuk masalah insentif, pemberian insentif perlu diperlakukan lebih setara antara satu karyawan dengan karyawan lain agar tidak menimbulkan konflik terhadap karyawan.

4. Bagi Program Studi S1 Manajemen Fakultas Ekonomi Universitas Prima Indonesia agar hasil penelitian ini dapat menjadi bahan studi kepustakaan, pembelajaran dan memperkaya penelitian ilmiah di Universitas Prima Indonesia. 


\section{DAFTAR PUSTAKA}

Bangun, Wilson. 2014. Manajemen Sumber Daya Manusia. Jakarta: Erlangga.

Daryanto. 2011. Ilmu Komunikasi. Bandung :Penerbit PT Sarana Tutorial Nurani Sejahtera.

Edison, dkk. 2017. Manajemen Sumber Daya Manusia. Bandung : Penerbit Alfabeta

Ghozali, Imam. 2013. Aplikasi Analisis Multi variate Dengan Program IBM SPSS 21. Jakarta :Penerbit Universitas Diponegoro

Herlambang, Susatyo. 2014. Perilaku Organisasi Cara Mudah Mempelajari Perilaku Manusia Dalam Sebuah Organisasi. Yogyakarta :Penerbit Gosyen Publishing

Kasmir. 2016. Manajemen Sumber Daya Manusia (Teori dan Praktek). Jakarta :Raja Grafindo Perkasa.

Kaswan. 2012. Manajemen Sumber Daya Manusia untuk Keunggulan Bersaing Organisasi. Yogyakarta :Graha Ilmu

Mangkunegara, Anwar P. 2013 Manajemen Sumber Daya Manusia Perusahaan. Bandung: Remaja Rosdakarya.

Moeheriono. 2014. Indikator Kinerja Utama. Jakarta: Rajawali Pers

Noor, Juliansyah.2013.Penelitian Ilmu Manajemen. Cetakan Kesatu, Jakarta :Kencana Media Group,

\section{Priansa, Donni Juni. 2016. Perencanaan dan Pengembangan SDM. Bandung: Alfabeta.}

Rivai dan Ella. 2011. Manajemen Sumber Daya Manusia Untuk Perusahaan. Jakarta: PT. Rajagrafindo Persada

$$
\begin{array}{llr}
\text { Rivai } & \text { dan Mulyadi. } & 2011 . \\
& \begin{array}{l}
\text { Kepemimpinan dan } \\
\text { Prganisasi. Edisi }
\end{array} & \text { Ketiga. } \\
\text { Organisan } & \text { Eetakan Kedelapan. Jakarta: PT. } \\
& \text { Rajagrafindo Persada }
\end{array}
$$

Siagian, Sondang P. 2015. Manajemen Sumber Daya Manusia. Edisi Ketiga. Cetakan kedua belas. Jakarta: Bumi Aksara.

Sopiah. 2008. Perilaku Organisasional. Edisi Pertama. Yogyakarta: Penerbit Andi

Sugiyono. 2010. Metode Penelitian Bisnis, Bandung :PenerbitAlfabeta

Sujarweni, V. Wiratna. 2014. Metodologi Penelitian. Yogyakarta: Pustaka Baru Press.

Sunyoto, Danang. 2013. Teori Kuesioner, dan Proses Analisis Data Perilaku Organisasional. Yogyakarta :Penerbit PT Caps

Sutrisno, Edy. 2015. Budaya Organisasi. Cetakan Keempat. Jakarta : Penerbit Kencana

Umam, Khaerul. 2012 Perilaku Organisasi. Cetakan Kedua, Bandung : CV. Pustaka Setia,. 
Wibowo, 2014. Manajemen Kinerja.

Edisi Keempat, Jakarta : PT

Rajagrafindo Persada

Wijayanto, Dian. 2012. Pengantar

Manajemen .Jakart : PT Gramedia

Yani, M. 2012. Manajemen Sumber Daya Manusia. Jakarta; Mitra Wacana.

Yunsepa dan Joni. 2013. Pengaruh Insentif dan Budaya Organisasi Terhadap Kinerja Karyawan PT. Perkebunan Mitra Ogan Baturaja. ISSN 2088-5644. 